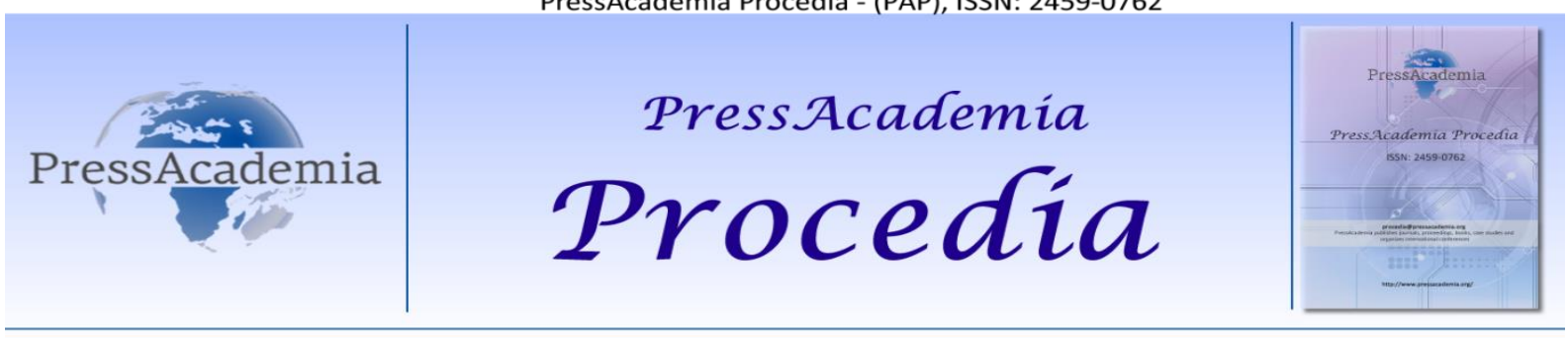

Global Business Research Congress (GBRC), May 24-25, 2017, Istanbul, Turkey

\title{
EVALUATION OF M GENERATION UNIVERSITY STUDENTS ABOUT EMPLOYER BRANDING
}

\author{
DOI: 10.17261/Pressacademia.2017.639 \\ PAP- GBRC-V.3-2017(65)-p.630-639 \\ Alperen Timucin Sonmez ${ }^{1}$, Ceyda Karatas ${ }^{2}$ \\ ${ }^{1}$ Bozok Universit, Erdogan AKDAG Campus, Yozgat. alperentimucin.sonmez@bozok.edu.tr \\ 2Balıkesir University, Cagis Campus, Balıkesir. ceydakrts@gmail.com
}

To cite this document

Sonmez, A. T., and C. Karatas (2017).Evaluation of M generation university students about employer branding. PressAcademia Procedia (PAP), V.3, p.630-639.

Permemant link to this document: http://doi.org/10.17261/Pressacademia.2017.639

Copyright: Published by PressAcademia and limited licenced re-use rights only.

\begin{abstract}
Within the framework of industrial development, the competition instruments of firms have also been differentiated. Because companies have started to produce similar products using similar technologies. In addition to classical competition variables such as product, price, technology and capital, their proper management has become a priority for businesses. In this respect, having qualified and equipped employees has become important in terms of providing competitive advantage. In this respect, enterprises start to brand institutional structures by giving priority to functional, psychological and economical benefits. This is the concept of employer branding. M generation is the closest generation to working life today. In this study, expectation levels will be determined from the workplaces where members of the $\mathrm{M}$ generation work in the future in terms of employer branding. In the study, frequency and percentages of the data to be collected by the questionnaire method will be analyzed from the students of the M generation in Bozok University. At the end of the study, it is aimed to produce information about which aspects need to be prioritized in order to market the institutional aspects of the enterprises that will start to work with $\mathrm{M}$ generation members in the next few years.
\end{abstract}

Keywords: M generation, age generations, employer, branding, employer branding.

JEL Codes: M12, M31, M39

\section{KUŞAĞı ÜYESI ÜNIVERSITE ÖĞRENCILERININ IŞVEREN MARKALAŞMASI HAKKINDAKi DEĞERLENDIRMELERi}

\section{ÖZET}

Endüstriyel gelişmeler çerçevesinde firmaların rekabet enstrümanları da farklılaşmıştır. Çünkü firmalar benzer teknolojileri kullanarak benzer ürünler üretebilmeye başlamıştır. Ürün, fiyat, teknoloji, sermaye gibi klasik rekabet değişkenlerinin yanı sıra bunların doğru yönetilmesi de işletmeler için bir öncelik halini almıştır. Bu açıdan nitelikli ve donanımlı çalışanlara sahip olma konusu, rekabet avantajı sağlamak açısından önemli bir hal almıştır. İşletmeler bu açıdan fonksiyonel, psikolojik ve ekonomik faydalarını ön plana çıkararak kurumsal yapılarını markalaştırmaya başlamış, bu da işveren markalaşması kavramını doğurmuştur. $M$ kuşağı ise günümüzde çalışma hayatına en yakın kuşaktır. Bu çalışmada $M$ kuşağı üyelerinin işveren markalaması açısından, gelecekte çalışacakları işyerleri hakkındaki beklenti düzeyleri tespit edilecektir. Çalışmada Bozok Üniversitesi'ndeki M kuşağı üyesi öğrencilerden anket yöntemi ile toplanacak veriler frekans ve yüzdeleri alınarak analiz edilecektir. Çalışma sonunda, önümüzdeki birkaç yıl içerisinde $\mathrm{M}$ kuşağı üyeleri ile çalışmaya başlayacak olan işletmelerin kurumsal yönlerini pazarlayabilmek için hangi yönlerini ön plana çıkarmaları gerektiği konusunda bilgiler üretmek amaçlanmaktadır.

Anahtar Kelimeler: M kuşağı, yaş kuşakları, işveren, markalaşma, işveren markalama JEL Kodları: M12, M31, M39 


\section{GíRiş}

Hem yönetim bilimi hem de yaş kuşakları insanlık tarihinin her döneminde ilgi çekmeyi başarmış konulardır. Ünlü filozof Aristoteles'in (MÖ 470-399) "Bugünün gençleri lüks ve gösteriş düşkünü, saygısız, geveze başkaldıran ve doyumsuzdur"(Semerci, 2013) sözü ve Sümer Çivi Yazıtlarındaki (MÖ 3500-4000) “Ne olacak bu gençliğin hali?” (Cantürk, www.sabah.com.tr) sorusu yaş kuşakları konusunun tarihi alt yapısını açıkça ortaya koymaktadır. Nitekim yaş kuşaklarıyla ilgili ilk yazılı kaynakların Eski Mısır Uygarlığına kadar uzanması da bu konunun köklü olduğunu destekler niteliktedir. Modern yönetim düşüncesinin yerleşmesiyle beraber işletmeler de klasik yapıdan, atölye tipi üretim hatlarından sıyrılmış, daha kompakt bir hal almaya başlamıştır. Bu da kapalı bir sistem olarak, iç yapılarında kapsamlı değişikliklere yol açmıştır. Özellikle 2. Dünya Savaşı sonrasında yaşanan ekonomik, teknolojik, sosyal ve siyasal gelişmeler işletmeleri bu yapılarından da kurtarmış ve açık bir sistem haline getirmiştir. Böylece çalışanların ve etkileşim halinde olunan toplumun ihtiyaç ve istekleri de rekabet avantajı kazanmak açısından önemli bir hal almıştır. 1980'li yılların sonlarında dünyadayaşanan tek kutupluluğa geçiş, globalizasyon ve teknolojik sıçramalar da bu rekabetin biçimini daha da değiştirmeye yetmiştir. Rekabet argümanlarının giderek başkalaşması, kullanılan yöntemlerin ürün düzeyini de aşarak tüm kuruma dağımasına yol açmıştır. Bu şekilde kullanılan kavramlar da yerini daha multidisipliner kavramlara bırakmıştır. Bu kavramlardan biri olan işveren markalaşması, ürünler üzerine yapılan markalaşma çabalarının iç müşterilere yöneltilmiş halini ifade etmektedir. Çünkü işletmeler günümüzde, rekabet üstünlüğünü elde edebilmek için en önemli rekabet argümanının nitelikli iş gücü olduğunun farkına varmışlardır. Üretim teknolojilerinin tüm ölçekteki işletmeler tarafından rahat bir şekilde bulunup kullanılmaya başlanmasıyla ürün kalite ve maliyeti üzerinden yapılan rekabetçi yaklaşımlar yerini nitelikli insan gücüne sahip olma yoluyla rekabete bırakmıştır. Bu çalışmada da şu anda işgücü oluşturmayan ancak ekonomik hayata katılacak olan en yakın kuşak olan $\mathrm{M}$ kuşağı üniversite öğrencilerinin işveren markalaşması ve alt boyutlarını algılama ve değerlendirmelerini ölçümlemek amaçlanmıştır.

\section{LITERATÜR INCELEMESI}

Kuşak, aynı tarihsel zaman aralığında doğan, belli bir sosyal gruba ait veya aynı sosyo-ekonomik hareketlere sahip zaman aralıklarına mensup olanlar olarak ifade edilebilmektedir. Kuşaklar sahip oldukları yetişme tarzları ve ortam değişikliklerinden dolayı birbirleri arasında hem karakter, hem iş görme yöntemleri, hem de sosyal hayatlarında önemli ayrışmalara sahiptir (Adıgüzel vd., 2014, s. 166). Kuşak kavramının biyolojik temelli tanımı, "ebeveynlerin ve çocukların doğumları arasında geçen ortalama zaman aralığı" şeklindedir (Keleş, 2011, s.130). Bu açıdan bakıldığında, geçmişte her 2025 yıllık dönemde bir nesil yetişirken, günümüzde çocuk sahibi olma yaşının giderek büyümesiyle birlikte bahsi geçen yaş aralığı da anlamını yitirmiştir. Biyolojik temelli yaklaşım geçmişte sosyologlara oldukça fazla hizmet etmiştir. Ancak değişen toplumsal yapı ve çevresel koşulların kuşaklar arasındaki sürenin uzaması ya da kısalmasına neden olabilecek çok sayıda faktörü de beraberinde getirmesi, biyolojik temelli kuşak kavramı üzerine tekrar düşünmeyi gerekli kılmıştır (Özer vd., 2013, s.124). Yapılan sosyolojik tanımlar incelendiğinde, kuşak, belli tarihlerde doğmuş, sosyalleşme sürecinde ortak sosyal, politik, ekonomik vb. olaylardan etkilenmiş, koşullar gereği benzer sorumluluklar yüklenmiş olduklarından dolayı ortak değer, inanç, beklenti ve davranışlara sahip gruplar olarak açıklanabilmektedir (Lower, 2008; Mannheim, 1952; Joshi, Dencker, Franz 2011). Kuşak kavramına Mannheim (1952)'ın yaptığı tanımdan hareketle yaklaşan araştırmacılar, kavramı biçimlendiren iki önemli unsura dikkat çekmektedir. Bunlardan ilki tarihsel olarak sahip olunan ortak konum, ikincisi ise bu tarihsel süreç içerisinde yaşanan olaylar ve deneyimlerin biçimlendirdiği ortak bilinçtir. Gençlik çağındaki bireylerin tarihsel süreç içerisinde karşılaştıkları ulusal ve uluslararası olaylar ortak belleklerin oluşmasına neden olmaktadır. Bu ortak bellek de gelecekteki eğilim, tercih ve davranışları şekillendirmektedir (Sönmez, 2015, s.8).

M Kuşağı: 1995-2003 arasında doğanlar olarak ele alınan M kuşağı, önemli bir ara kuşaktır (Sönmez, 2015, s.30). Biyolojik yaklaşım ile ele alındığında, yaş kuşaklarının 20 yıldan önce değişme göstermediği bilinmesine rağmen, günümüz dünyasındaki hızlı değişimler söz konusu kuşağın gelişimini hazırlamıştır (Ayhün, 2013, s.101-102).

$M$ kuşağı tam bir teknoloji dostu olmasının ötesinde, zor beğenen, bireysel bir dünya vatandaşıdır. X kuşağı üyesi olan anne ve babalarına kıyasla önemli farklııklar taşıyan bu kuşak üyeleri PC, GSM ve internet çocukları olarak da ifade edilmektir (Senbir, 2004, s.26). Bir yandan müzik dinlerken bir yandan internet üzerinden haberlere bakan, diğer yandan da arkadaşlarıyla sohbet eden bu nesil teknoloji ile ayrılmaz bir bütün oluşturmakta ve telefon, internet, takvim, müzik çalar gibi uygulamaları bir arada bulunduran cep bilgisayarlarını yanlarından ayırmazlar. Bir tüketici olarak da almak istedikleri ürünün en ucuzunu ve en kalitelisini bulmak için internetten kıyas yolunu seçerler. Bu yönleriyle $M$ kuşağı üyeleri, yeniliklerden haberdar, her şeyi bilen, yetenekli fakat yalnız ve içine kapanıktır. Tüm hayatlarını bir bilgisayar ekranına sığdırabilirler. Çeşitli proje yarışmalarına katılan, girişimcilik eğitimi gören bu kuşak, sosyal ağların gücünü keşfetmiş, 
teknolojiyi hayatlarının merkezine oturtmuş, yalnız bir kuşaktır. İnternet üzerinden gördükleri teşvikler ve aldıkları girişimcilik eğitimleri sayesinde internet girişimcisi olma adayıdırlar (Yelkikalan vd., 2010, s. 501-502).

İşveren Markalaşması: İşletmelerin Dünya'daki değişim ve gelişimlerden en üst düzeyde etkilenmesi, son derece üretken ve dinamik bir yapıya kavuşmalarını sağlamıştır. Pazardaki sert rekabet koşullarında ayakta kalabilmek için tüm yönetim süreçlerinde değişim çağına uygun yenilikler getiren işletmeler aynı zamanda marka kavramını da genişleterek mamül ve hizmetlerini markalaştırdıkları gibi kurumsal yapılarını da markalaştırmak zorunda kalmıştır. Günümüzde kurum kimliklerini etkili bir biçimde markalaştırmayı başaran işletmeler, Pazar/ürün yaşam eğrisi üzerinde rakiplerinden farklılaşmayı ve rekabet üstünlüğü sağlamayı başarabilmişlerdir(Doğru ve Çakır, 2015, s.675).

İşveren markası, bir şirketin kendisini işveren olarak farklı ve çekici kılan özelliklerine ilişkin örgüt içinde ve dışında yürüttüğü çabalardır. İşveren markası, bir örgütün aday havuzunda bulunan kişiler ve örgütte hali hazırda çalışanlar tarafından nasıl algılandığı ile ilgilenir. Potansiyel adayların ve mevcut çalışanların örgütü nasıl algıladıklarını bilmek hem daha kaliteli adayların seçilmesini sağlamakta hem de mevcut nitelikli çalışanları elde tutmaya yardımcı olmaktadır (Aras ve Bayraktaroğlu, 2016 s. 602).

Genel bir tanımlama ile İşveren Markası, bir firmanın çalışabilecek en iyi firma olduğu algısıdır. Firmanın personelleri, aday personeller, yönetim kurulu ve ortaklar, toplumun gözünde yarattı̆̆ı algıdan oluşur. Tüm firmaları kapsayan, genel bir işveren markası tanımı yoktur, çalışan profili, kurum kültürü ve stratejik hedeflere göre belirlenir. Yeni çalışanların firmaya kazandırımasında işveren markasının doğru yönetilmesinin önemli bir rolü vardır. Firma hakkında algılar, yetenekli personelleri firmaya çekmektedir. En gözde şirketler listeleri, adayları cezp etmek için rekabet edebilen platformlara dönüşmüştür (Demir, 2014, s.13).

Yaş kuşakları literatürü incelendiğinde, çalışmaların $M$ kuşağını $Y$ kuşağı içerisinde değerlendirdiğini ve örgütlere kazandırdıkları davranış farklııkları çalışma tarzları ve yeni iş değerleri üzerine odaklandıkları görülmüştür (Aydın ve Başol, 2000; Keleş, 2011; Çemberci vd, 2014; Özer vd, 2013; Adıgüzel vd, 2014).

\section{VERI VE YÖNTEM}

Araştırma tanımlayıcı nitelikte olup, Bozok Üniversitesi Sağlık Hizmetleri Meslek Yüksekokulu’nda yükseköğrenim gören öğrencilerine anket uygulanarak alınan verilere amaca ve verinin yapısına uygun istatistik teknikler uygulanarak değerlendirme verileri elde edilmiştir.

Araştırma örnekleminin belirlenmesinde olasılıklı örnekleme yöntemlerinden basit raslatısal örnekleme kullanılmıştır. 20162017 akademik yııında Bozok Üniversitesi Sağıık Hizmetleri Meslek Yüksekokulu'nda kayıtlı 765 öğrenci bulunmaktadır. Yapılan çalışma sosyal bir araştırma olduğundan \%5 hata payı ve \%10 güven aralığında (Kurtuluş, 2004) örneklem hesaplaması yapılması yeterli görülmüştür. Öğrenciler tarafından cevaplanması için toplam 150 anket yüksekokula verilmiş, bu anketlere 118 adet dönüş yapılmıştır. 17 adeti baz alınan M kuşağı doğum yılları (1995-2002) arasında olmadığından değerlendirme dışı bırakılmıştır. Böylece 101 adet anket değerlendirmeye alınmıştır.

İşveren markalaşmasının ölçülmesinde İçirgen (2016)'nın çalışmasında kullandığı, Ambler ve Barrow (1996), Knox ve Freman (2006), Backhause ve Tikoo (2004) çalışmalarında yer alan 23 ifade kullanılmıştır. Katılımcıların değerlendirmelerini ölçmek için ağılıklandırılmış likert ölçeği 1-Kesinlikle Katılmıyorum, 2-Katılmıyorum, 3-Ne Katılıyorum Ne Katılmıyorum, 4Katılıyorum, 5- Kesinlikle Katılıyorum şeklinde kullanılmıştır.

Araştırmada kullanılan ölçeklerin iç tutarlılığını ölçmek için alpha modeli( $\alpha)$ modeli güvenirlik analizi uygulanmıştır. Yapılan güvenirlik analizi sonuçları şu şekildedir:

Tablo 1: İşveren Markalaşması Ölçeği İçin Yapılan Günenilirlik Analizi Sonuçları

\begin{tabular}{|c|c|c|}
\hline ÖLÇEK & Cronbach's Alpha $(\boldsymbol{\alpha})$ & $\mathbf{N}$ \\
\hline İşveren Markalaşması & 0,945 & 23 \\
\hline
\end{tabular}

Tablo 1'den de görülebileceği gibi alpha modeline göre yapılan güvenirlik analizi sonucuna göre, 23 değişkeni olan ( $N=23$ ) İşveren Markalaşması ölçeğinin Crombach's Alpha $(\alpha)$ değeri 0.945 çıkmıştır. Bu sonuca göre alpha ( $\alpha$ ) değeri Hair vd. (2005) tatarfından önerilen 0.70 değerinin üzerinde olduğundan, kullanılan ölçeğin iç tutarlılı̆ının olduğu ve güvenilir bir ölçek olduğu anlaşılmaktadır. Kayış (2014)'a göre ise kullanılan ölçek Alpha ( $\alpha$ ) değeri 0.80 ve 1.00 arasında olduğu için, kullanılan 
ölçeğin yüksek derecede güvenilir bir ölçek olduğu söylenebilmektedir. İşveren Markalaşması ölçeğinin geçerliliğini test etmek için 23 ifadeye faktör analizi uygulanmıştır. Faktör analizini yapmadan önce, veri setinin bu analize uygun olup olmadığını anlamak için KMO ve Barlett testleri yapılmıştır. Yapılan testlere ilişkin sonuçlar Tablo 2'de gösterilmiştir.

Tablo 2: İşveren Markalaşması Ölçeği İçin Yapılan KMO ve Barlett Testleri Sonuçları

\begin{tabular}{|c|c|c|}
\hline ÖLÇEKLER & KMO TESTi (\%) & BARLETT TESTi (sig) \\
\hline İ̧sveren Markalaşması & 0,883 & 0,000 \\
\hline
\end{tabular}

Tablo'dan görüleceği gibi KMO Testi işveren markalaşması ölçeği ifadeleri için \%88.30'dur. Bu değer \%60'dan büyük olduğu için veri setinin faktör analizi için uygun olduğu sonucuna ulaşılabilmektedir. Yine Barlett testi sonucu da (sig. 0.000) anlamlı çıkmıştır. Bu da değişkenler arasında yüksek kolerasyon olduğunu göstermektedir. Barlett testi sonucu da değişkenlerin faktör analizi için uygun olduğunu göstermektedir. Ölçeğin geçerliliğini sınamak için yapılan faktör analizi sonucu oluşan faktör yükleri, toplam varyansları ve özdeğerleri Tablo 3'de gösterilmiştir.

Tablo 3: İ̧veren Markalaşması Faktör Analizi Sonuçları

\begin{tabular}{|c|c|c|c|}
\hline FAKTÖRLER VE DEĞIŞKENLER & Faktör Yükleri & Varyans (\%) & Öz Değerler \\
\hline $\begin{array}{l}\text { Algılanan Psikolojik } \\
\text { Fayda }\end{array}$ & & 25,434 & 10,559 \\
\hline İşveren Markalaşma-23 & 0,815 & & \\
\hline İşveren Markalaşma-19 & 0,811 & & \\
\hline İşveren Markalaşma-17 & 0,786 & & \\
\hline İşveren Markalaşma-20 & 0,757 & & \\
\hline İşveren Markalaşma-18 & 0,751 & & \\
\hline İşveren Markalaşma-16 & 0,751 & & \\
\hline İşveren Markalaşma-21 & 0,686 & & \\
\hline İşveren Markalaşma-22 & 0,618 & & \\
\hline İşveren Markalaşma-15 & 0,604 & & \\
\hline İşveren Markalaşma-14 & 0,494 & & \\
\hline İşveren Markalaşma-4 & 0,080 & & \\
\hline Algılanan İşlevsel Fayda & & 19,386 & 2,977 \\
\hline İşveren Markalaşma-3 & 0,836 & & \\
\hline İşveren Markalaşma-5 & 0,787 & & \\
\hline İşveren Markalaşma-1 & 0,738 & & \\
\hline İşveren Markalaşma-2 & 0,703 & & \\
\hline İşveren Markalaşma-6 & 0,641 & & \\
\hline İşveren Markalaşma-7 & 0,251 & & \\
\hline Operasyonel Fayda & & 17,616 & 1,362 \\
\hline İşveren Markalaşma-8 & 0,778 & & \\
\hline İşveren Markalaşma-9 & 0,722 & & \\
\hline İşveren Markalaşma-10 & 0,663 & & \\
\hline İşveren Markalaşma-12 & 0,662 & & \\
\hline İşveren Markalaşma-11 & 0,302 & & \\
\hline İşe Alım & & 7,327 & 1,147 \\
\hline İşveren Markalaşma-13 & 0,449 & & \\
\hline
\end{tabular}


İşveren markalaşması ifadeleri için yapılan faktör analizinde, özdeğeri birden büyük olan 4 boyut bulunmuştur. Bulunan boyutlara"Algılanan Psikolojik Fayda", "Algılanan İşlevsel Fayda", "Operasyonel Fayda" ve "işe Alım" isimleri verilmiştir. Açıklanan toplam varyansın $(\% 69,768), \% 60$ ’ı üzerinde olması ölçeğin geçerli olduğunu göstermektedir. Yani, ölçekteki ifadeler, etkileşimsel liderlik algısını ölçmekte yeterlidir.

\section{BULGULAR VE TARTIŞMA}

Yapılan istatistik analizlerin ardından elde edilen demografik bilgiler ve araştırmaya katılan cevaplayıılardan toplanan frekans ve yüzde değerleri aşağıdaki gibidir.

Tablo 4: Katılımcılara ilişkin Demografik Bilgiler

\begin{tabular}{|c|c|c|}
\hline & FREKANS & YÜZDE \\
\hline \multicolumn{3}{|c|}{ DOĞUM TARIHI } \\
\hline 1994 & 1 & 1,0 \\
\hline 1995 & 10 & 9,9 \\
\hline 1996 & 15 & 14,9 \\
\hline 1997 & 40 & 39,6 \\
\hline 1998 & 35 & 34,7 \\
\hline \multicolumn{3}{|c|}{ AYLIK HARCAMA } \\
\hline $0-450$ & 32 & 32,3 \\
\hline $451-700$ & 34 & 34,4 \\
\hline 701- 950 & 17 & 17,1 \\
\hline $950-+\infty$ & 16 & 16,2 \\
\hline \multicolumn{3}{|c|}{ CINSIYET } \\
\hline Kız & 71 & 70,3 \\
\hline Erkek & 30 & 29,7 \\
\hline \multicolumn{3}{|c|}{ BÖLÜM } \\
\hline $\begin{array}{c}\text { Sağlık Kurumları } \\
\text { I̧şletmeciliği }\end{array}$ & 43 & 42,6 \\
\hline Çocuk Gelişimi & 34 & 33,7 \\
\hline Yaşlı Bakımı & 24 & 23,8 \\
\hline \multicolumn{3}{|c|}{ SINIF } \\
\hline 1.SINIF & 52 & 51,5 \\
\hline 2.SINIF & 49 & 48,5 \\
\hline
\end{tabular}

Tablo incelendiğinde katılımcıların en fazla $(\% 34,4)$ 451-700 TL arasında harcama gerçekleştirmektedir. Bunu \%32,3 ile 200400 TL, \%17,1 ile 701-950 TL ve \%16,2 ile 950 TL ve üzeri izlemektedir. Çalışma, M kuşağı üyeleri üzerine yapılan bir araştırma olduğundan katıımcıların 1995 - 1997 yılları arası doğumlu olmaları beklenmekteydi. Bu çerçevede Cevaplayıcıların en büyüğü 1994, en küçüğü ise 1998 doğumludur. Yine Cevaplayıcıların \%70,3'ünün kız, \%29,7'sinin ise erkek öğrencilerden oluştuğu görülmektedir. Ayrıca çalışmaya en fazla katkıyı \%42,6'lık pay ile Sağlık Kurumları Işletmeciliği Bölümü’nün yaptığı, Çocuk Gelişimi $(\% 33,7)$ ve Yaşlı Bakımı $(\% 23,8)$ bölümlerinin de katkı sağlayan diğer bölümler olduğu sonucuna varılabilmektedir.

Cevaplayıcıların işveren markalaşması ve alt boyutlarına ilişkin algılamalarına ait ortalama ve standart sapmalar Tablo 5'de gösterilmiştir. 
Tablo 5: Katılımcıların İşveren Markalaşması Algılamaları Ortalama ve Standart Sapmaları

\begin{tabular}{|l|c|c|}
\hline & ORTALAMA & STANDART SAPMA \\
\hline \multicolumn{2}{|c|}{ işVEREN MARKALAŞMASI } \\
\hline $\begin{array}{l}\text { Algılanan Psikolojik } \\
\text { Fayda }\end{array}$ & $\mathbf{4 , 1 3}$ & $\mathbf{0 , 7 0}$ \\
\hline Algılanan İşlevsel Fayda & 4,03 & 0,81 \\
\hline Operasyonel Fayda & 4,09 & 0,85 \\
\hline İşe Alım & 4,10 & 0,80 \\
\hline
\end{tabular}

Tablodan da görüleceği üzere $M$ kuşağu üniversite öğrencilerinin işveren markalaşması ve alt boyutları ile ilgili algılamaları oldukça yüksektir. Ölçek bir bütün olarak ele alındığında, $M$ kuşağı üniversite öğrencilerinin işveren markalaşması değerlendirmeleri 4,13 olmuştur. Değerlendirmenin standart sapmasına bakıldığında $(0,70)$ bu ortalama değerinin yine olumlu değerlendirme sınırları içerisinde kaldığı görülmektedir. Konu alt boyutlar itibariyle incelendiğinde ise, yine tüm boyutların çok olumlu bir değerlendirme aldığı (Algılanan Psikolojik Fayda: 4,03, Algılanan İşlevsel Fayda: 4,23, Operasyonel Fayda: 4,09, İşe Alım: 4,10) gözlemlenebilmektedir. Ancak tüm boyutlar arasında algılanan işlevsel fayda boyutunun (ort: 4,23) en olumlu değerlendirmeyi aldığı, bu boyutu sırasıyla işe alım (ort:4,10), operasyonel fayda (ort: 4,09) ve algılanan psikolojik fayda (ort: 4,03) boyutlarının izledikleri görülmektedir. Bu boyutlar içerisinde standart sapması en yüksek olanı ise, işe alım boyutu olarak göze çarpmaktadır.

\section{SONUÇ}

Tarihin en eski kavramlarından biri olan yönetim kavramı, insanlık tarihi boyunca toplumsal dönüşümlerle beraber değişime uğramış ve bugünkü halini almıştır. Özellikle Sanayi devrimiyle beraber büyüyen işletmeler modern yönetim tarzı olan bilimsel yönetim kavramını ortaya atmış, bu zamandan sonra yaşanan tüm gelişmeler işletmelerin rekabet gücü ve avantajı sağlamak için gelişimlerinin önünü açmıştır. Tüm bu gelişmeler şüphesiz ki işletmelerin toplumsal, ekonomik, demografik, teknolojik, politik değişimler ışığında oluşan yeni sosyal yapılara uyum sağlama çabaları olarak da görülebilir. Neoklasik yönetim düşüncesinin hakimiyetiyle beraber açık sistemler haline gelen işletmeler, bir rekabet unsuru olarak toplumsal yapıya uyum göstermeyi amaç edinmiştir. Değişik rekabet araçlarının nitelikleri sıradanlaştıkça yeni rekabet unsurlarının gündeme gelmesi, hem bilimsel hem de sektörel mana da işletmecilik biliminin dinamizmini korumasına yardımcı olmaktadır. Son zamanlarda gündemde olan işveren markalaşması da bu dinamizmin bir sonucu olan rekabet araçlarından biridir. Aynı zamanda yaş kuşakları kavramı ve kuşaklar teorisi de kalite ve her zaman ilk seferinde en iyiyi bulmaya çalışan işletmeler için farklı bir rekabet enstrümanı haline gelmiştir. En nitelikli çalışanlara sahip olup bunları en iyi yönlendiren ve personel devir hızını düşürebilen işletmeler rekabet avantajını ürünlerinden de önce elinde bulundurabilmektedir.

$\mathrm{Bu}$ açıklamalar çerçevesinde, bu çalışmada $\mathrm{M}$ kuşağı üniversite öğrencilerinin işveren markalaşması algılamaları araştırılmıştır. Elde edilen bulgulara göre katılımcıların işveren markalaşması ile ilgili algılamalarının yüksek derecede olumlu olduğu sonucuna ulaşılmıştır. Konu alt boyutlar itibariyle ele alındığında, en olumlu değerlendirmenin algılanan işlevsel fayda boyutunayapıldığı görülmektedir. Buna göre yetenekli, meraklı, yenilikçi, girişimci olarak nitelenen $\mathrm{M}$ kuşağı üyeleri yeni mezunlar için cazip fırsatlar sunan sektör liderleri ile çalışma eğilimindedir. Ayrıca çalışanlarına karşı ilgili, samimi davranan kişilerin yönetici olduğu, çalışanlar arasında ve üstlerle iyi ilişkiler geçirilen işletmeler tercih edilmektedir. Tüm bunlar sağlnadığında, $M$ kuşağı üyeleri de başarılı olabilmek için daha fazla çaba göstermeye hazır hale gelmektedir. Tüm olumlu vasıflarına rağmen yalnız ve içine kapanık olan bu nesilin, algılanan işlevsel fayda boyutunun tüm özellikleriyle ilgi beklediği söylenebilmektedir. Aynı şekilde algılanan psikolojik fayda boyutunda da sosyal ve psikolojik ihtiyaçlarının karşılanması durumunda sadık bir çalışan olma eğiliminde oldukları söylenebilmektedir. Ayrıca yöneticilerinin lider vasıflı, yetkin ve yenilikçi bir imaj çizmeleri gerekliliği de bulgulardan çıkarılabilecek bir başka sonuçtur. Açıklamaların tamamı bir arada değerlendirildiğinde ise, M kuşağı üyelerinin işyerindeki psikolojik faydalara büyük önem vermesinin (var: 25,434) yanı sıra bunları fiilen yaşamak istediği (algılanan işlevsel fayda ort:4,23) anlaşılmaktadır. Çalışmanın sadece Bozok Üniversitesi Sağlık Hizmetleri Meslek Yüksekokulu'nda yapılması alan olarak en büyük kısıtıdır. Ayrıca sadece M kuşağının ele alınması, bu kuşak çalışanları için işletmelerin kendilerini nasıl pazarlaması gerektiği konusunda bilgi sunulsa da bu kuşağın öncekilere kıyasla, yönetim usulleri konusunda tam olarak hangi farklılıklar aradığı konusunda tam bir fikir oluşmasını engellemektedir. Gelecek çalışmalar konunun bu yönlerine de odaklanabilir. 


\section{KAYNAKLAR}

Adıgüzel, O., Batur H. Z., Ekşili, N. (2014). Kuşakların Değişen Yüzü ve Y Kuşağı ile Ortaya Çıkan Yeni Çalışma Tarzı: Mobil Yakalılar. Süleyman Demirel Üniversitesi Sosyal Bilimler Enstitüsü Dergisi, 1 (19). s. 165-182.

Ambler, T., \& Barrow, S. (1996). The employer brand. Journal of brand management, 4(3), 185-206.

Aras, M., Bayraktaroğlu, S., (2016), "Iş̧veren Markası Bağlamında Fonksiyonel ve Duygusal Faydanın Örgütsel Bağlılığa Etkisi”, 24. Yönetim ve Organizasyon Kongresi, 29-31 Mayıs, İstanbul.

Aydın, G., Başol, O. (2014), “X ve Y Kuşağı: Çalışmanın Anlamında Bir Değişme Var mı?”, Electronic Journal of Vocational Colleges” s. 1-15.

Ayhün, S., (2013), “Kuşaklar Arasındaki Farklılıklar Ve Örgütsel Yansımaları”, Ekonomi ve Yönetim Araştırmaları Dergisi, 2 (1), s. $93-112$.

Backhaus, K., \& Tikoo, S. (2004). “Conceptualizing and researching employer branding”, Career development international, 9(5), 501-517.

Cantürk, T. Çalışan Uyumu, BP-X-Y Denklemi. http://www.sabah.com.tr/yazarlar/cumartesi/bsemerci/2013/08/03/gelismek-icin-degismek$\underline{\text { sart }}$

Çemberci, M., Sudak, M., Aş̧̧ı, S., Civelek, M. (2014), "Y Neslinin Örgüt Ortamındaki Davranış Farklılıklarının Analizi”, Academic Journal of Information Technology, 5 (15), s. 58-73.

Demir, M., (2014), “İ̧̧veren Markası ve İşveren Markasının Çalışan Memnuniyeti Üzerine Etkisi”, Bahçeşehir Üniversitesi, Yayınlanmamış Yüksek Lisans Tezi, İstanbul.

Doğru, G., Yeygel Çakır, S., (2015), “İşveren Markasi Yönetim Sürecinde Strateji Ve Uygulamalarin İncelenmesi: Türkiye'deki Şirketlerin İnsan Kaynaklari Yöneticilerine Yönelik Bir Araştirma”, Uluslararası Sosyal Araştırmalar Dergisi, 8 (40), s. 674-689.

Hair, F.J., C.W. Black, J.B. Babin, E.R. Anderson ve L.R. Totham (2005), Multivariate Data Analysis, PersonPrenticeHall, Sixth Edition, New Jersey.

İçirgen, H., (2016), “ İşveren Matrkası ve İnsan Kaynakları Yönetimi Uygulamalarının İşten Ayrılma Niyetine Etkileri: Turuzm Sektörü Üzerine Bir Araştırma”, Başkent Üniversitesi Sosyal Bilimler Enstitüsü, Yayınlanmamış Yüksek Lisans Tezi, Ankara.

Joshi, A.,Dencker, J. C., Franz, G. (2011). Generations in Organizations. Research in OrganizationalBehavior, (31). s. 177-205.

Kayış, A. (2014), Güvenilirlik Analizi, Şeref Kalaycı (ed.), SPSS Uygulamalı Çok Değişkenli İstatistik Teknikleri, Ankara: Asil Yayın Dağıtım.

Keleş, H. N. (2011). Y Kuşağı Çalışanlarının Motivasyon Profillerinin Belirlenmesine Yönelik Bir Araştırma. Organizasyon ve Yönetim Bilimleri Dergisi, 3 (2). s. 129-139.

Knox, S., \& Freeman, C. (2006). "Measuring and managing employer brand image in the service industry", Journal of Marketing Management, 22(7-8), 695-716.

Kurtuluş, K., (2004), Pazarlama Araştırmaları, Litteratür Yayıncılık, İstanbul.

Lower, J. (2008). Brace Yourself Here ComesGeneration Y. CricicalCareNurse, 28 (5). s. 80-85.

Mannheim, K. (1952). The Problem of Generations. Chapter VII. Reutledge Republished.

Özer, P.S., Eriş, E. D., Özmen, Ö. N. (2013). Kuşakların Farklılaşan İş Değerlerine İlişkin Emik Bir Araştırma. Dumlupınar Üniversitesi Sosyal Bilimler Dergisi, (38). s. 123-141.

Semerci, B. (2013, 3 Ağustos). Gelişmek için Değişmek Şart. http://www.sabah.com.tr/yazarlar/cumartesi/bsemerci/2013/08/03/gelismekicin-degismek-sart.

Senbir, Hakan, Z Son İnsan mı ?, İstanbul : Okuyan Us Yayınları, 2004.

Sönmez, A., T. (2015), "Tüketicilerin Yaş Kuşaklarına Göre Marka Faydası, Marka Sadakati, Marka Aşkı ve Marka Kişiliği Değerlendirmeleri” Bozok Üniversitesi Sosyal Bilimler Enstitüsü, Yayınlanmamış Yüksek Lisans Tezi, Yozgat.

Yelkikalan, N.,Akatay, A., Altın, E. (2010). "Yeni Girişimcilik Modeli Ve Yeni Nesil Girişimci Profili: İnternet Girişimciliği ve Y, M, Z Kuşağı Girişimci". Selçuk Üniversitesi Sosyal ve Ekonomik Araştırmalar Dergisi, 14 (20). s. 490-506. 